(c) American Dairy Science Association, 2004.

\title{
Effect of the Metabolism of Urea on the Acidifying Activity of Streptococcus thermophilus
}

\author{
S. Pernoud, ${ }^{1}$ C. Fremaux ${ }^{2}$ A. Sepulchre, ${ }^{2}$ G. Corrieu, ${ }^{1}$ and C. Monnet ${ }^{1}$ \\ ${ }^{1}$ Unité Mixte de Recherche Génie et Microbiologie des Procédés Alimentaires, \\ Institut National de la Recherche Agronomique, \\ 78850 Thiverval-Grignon, France \\ ${ }^{2}$ Rhodia-Food, 86220 Dangé Saint Romain, France
}

\begin{abstract}
One of the main functions of Streptococcus thermophilus strains used in the dairy industry is the production of lactic acid. In cheese and fermented milk manufacturing processes, the $\mathrm{pH}$ evolution kinetics must be reproducible in order to ensure the good quality of the final products. The objective of the present study was to investigate the effect of the metabolism of urea on the acidifying activity of fast- and slow-acidifying strains of $S$. thermophilus. Milk treatment with a purified urease and utilization of the urease inhibitor flurofamide revealed that urea metabolism by $S$. thermophilus influences the $\mathrm{pH}$ evolution kinetics through 2 distinct means. First, ammonia production from urea tends to increase the $\mathrm{pH}$. This effect is greater when lactic acid concentration is low due to a lower buffering capacity of milk. Second, urea metabolism also modifies growth and lactic acid production by $S$. thermophilus. Depending on the strains and the growth stage of the cultures, consumption of urea induces either a faster or a slower $\mathrm{pH}$ decrease. For the slow-acidifying strain RD678, suppression of urea metabolism by adding flurofamide decreased the time necessary to reach $\mathrm{pH}$ 6 by $195 \mathrm{~min}$. This effect was less pronounced for the 2 fast-acidifying strains RD674 and RD677. These results show that urea metabolism may have a considerable influence on the acidifying properties of $S$. thermophilus strains.
\end{abstract}

(Key words: lactic acid bacteria, Streptococcus thermophilus, acidifying activity, urea)

\section{INTRODUCTION}

The lactic acid bacterium Streptococcus thermophilus is used in the manufacture of several kinds of cheeses and fermented milks, in which its main functions are

Received July 1, 2003.

Accepted September 17, 2003.

Corresponding author: C. Monnet; e-mail: monnet@grignon. inra.fr. the production of lactic acid, aroma compounds, and exopolysaccharides. Lactic acid assists in milk coagulation and curd draining, imparts a fresh acid flavor to fermented milks, and helps to suppress the growth of pathogens and spoilage microorganisms.

In contrast to the other lactic acid bacteria used as starter cultures, $S$. thermophilus possesses a urease, which converts urea into ammonia and carbon dioxide (Juillard et al., 1988; Tinson et al., 1982). During the growth of S. thermophilus in milk, production of ammonia from urea slows down the $\mathrm{pH}$ decrease or induces a temporary increase of $\mathrm{pH}$ (Tinson et al., 1982; Spinnler and Corrieu, 1989; Latrille et al., 1992). The presence of urease is not essential for the growth of $S$. thermophilus, as a naturally occurring urease-deficient strain has been described (Juillard et al., 1988).

Urea concentration in milk depends on several factors such as the bovine breed, the stage of lactation, the season, and the nitrogen balance of the diet (de Peters and Ferguson, 1992). Milk urea nitrogen can be used to estimate urinary nitrogen excretion and the target range for milk urea concentration of Holstein cows is between 1.4 and $1.9 \mathrm{mM}$ (Kohn et al., 2002). Variations of the urea content of milk affect the $\mathrm{pH}$ evolution kinetics during the manufacture of cheeses and fermented milks when $S$. thermophilus strains are used. As a consequence, several important sensory properties of the dairy products may be affected. For example, a high urea content in milk may lead to Reblochon cheeses with a higher moisture content (Martin et al., 1997).

Despite its implications in cheese making, the metabolism of urea by $S$. thermophilus, and especially its effect on the $\mathrm{pH}$ evolution kinetics during the fermentation of milk, has been seldom investigated. In this study, we aimed to characterize the effect of urea on the acidifying activity of fast- and slow-acidifying $S$. thermophilus strains. The first type of strains is often used in the manufacture of yogurt and hard cheeses, whereas the latter type is often used for the production of soft cheeses. 


\section{MATERIALS AND METHODS}

\section{Strains}

Streptococcus thermophilus RD672, RD674, RD677, and RD678 were obtained from Rhodia Food (Dangé Saint Romain, France). RD672 and RD678 are slowacidifying strains of $S$. thermophilus, whereas RD674 and RD677 are fast-acidifying strains. Streptococcus thermophilus CNRZ407 was obtained from the collection of the Institut National de la Recherche Agronomique (Jouy-en-Josas, France).

\section{Measurement of the Acidifying Activity}

After cultivation for $24 \mathrm{~h}$ at $37^{\circ} \mathrm{C}$ in $5 \mathrm{~mL}$ of $\mathrm{M} 17$ broth (Terzaghi and Sandine, 1975), the strains were inoculated at $2 \%(\mathrm{vol} / \mathrm{vol})$ in $5 \mathrm{~mL}$ of reconstituted skim milk (100 g/L; Elle et Vire, Condé-sur-Vire, France) that had been sterilized for $10 \mathrm{~min}$ at $110^{\circ} \mathrm{C}$. The cultures were incubated for $24 \mathrm{~h}$ at $37^{\circ} \mathrm{C}$ and inoculated at $1 \%$ in $150 \mathrm{~mL}$ of reconstituted skim milk (100 g/L; Elle et Vire, Condé-sur-Vire, France) that had been heated for 10 min at $90^{\circ} \mathrm{C}$. The culture flasks were then placed in a water bath at $37^{\circ} \mathrm{C}$ and the $\mathrm{pH}$ was continuously measured during $15 \mathrm{~h}$ using a CINAC apparatus (Ysebaert, Frépillon, France). The acidification rate (dpH/dt) was calculated from these data and expressed as $\mathrm{pH}$ units/min (Spinnler and Corrieu, 1989). The urease inhibitor flurofamide (Kenny, 1983) (N-[diaminophosphinyl]-4-flurobenzamide; ICN, Orsay, France), was used at a final concentration of $10 \mu \mathrm{M}$. A concentrated stock solution of this compound was prepared at $400 \mu M$ and added to milk after sterilization by filtration $(0.22 \mu \mathrm{m})$. All experiments were done in triplicate.

\section{Measurement of Growth and Biochemical Analyses}

Absorbance of the milk cultures after $15 \mathrm{~h}$ of growth was measured by clarification of the medium (LevataJovanovic and Sandine, 1996). The sample was diluted $(1 / 10, \mathrm{vol} / \mathrm{vol})$ with a solution of ethylenediaminetetraacetic acid (EDTA) at $2 \mathrm{~g} / \mathrm{L}$ whose $\mathrm{pH}$ was adjusted to 12.5 with sodium hydroxide $(10 \mathrm{M})$, and absorbance was then read at $405 \mathrm{~nm}$. The difference between the absorbance of the sample and that of noninoculated milk treated in the same conditions was calculated.

Ammonia, urea, and lactic acid were assayed using enzymatic kits (Boehringer, Boehringer Mannheim $\mathrm{GmbH}$, Mannheim, Germany) according to the manufacturer's instructions. Before the assays, the samples were centrifuged for $20 \mathrm{~min}$ at $21,000 \times g$ and the supernatants were recovered. Carbon dioxide was measured using a previously described method (Monnet et al., 2002).

\section{Milk Titration}

Titration curves were established by measuring the $\mathrm{pH}$ after addition of lactic acid $(500 \mathrm{~g} / \mathrm{L})$ in $60-\mu \mathrm{L}$ increments to a conical flask containing $250 \mathrm{~mL}$ of milk at $37^{\circ} \mathrm{C}$. The milk (which was not inoculated with $S$. thermophilus) was continuously stirred and acid was added approximately every $30 \mathrm{~s}$ to allow for equilibrium (Lucey et al., 1993). Titration was also done after treatment of milk with $1.36 \mathrm{U} / \mathrm{mL}$ of jack bean urease (Sigma, Saint-Quentin-Fallavier, France) for $3 \mathrm{~h}$ at $37^{\circ} \mathrm{C}$. During the experiment, there was no significant loss of ammonia and carbon dioxide by volatilization. All experiments were carried out in triplicate.

\section{RESULTS}

\section{Effect of Urea Hydrolysis on the pH of Milk}

To evaluate the impact of urea hydrolysis on the $\mathrm{pH}$, we treated reconstituted skim milk (initial $\mathrm{pH}$ was 6.52) with urease, as described in Materials and Methods. This treatment resulted in a $\mathrm{pH}$ increase of 0.28 unit (U). Urea hydrolysis thus has a considerable effect on the $\mathrm{pH}$ of milk. During urea consumption by S. thermophilus, lactic acid is also produced, which decreases the $\mathrm{pH}$. As the buffering capacity of milk depends on the $\mathrm{pH}$ (Lucey et al., 1993), it is possible that the effect of urea hydrolysis on $\mathrm{pH}$ is not the same when it occurs early during cultivation as when it occurs late. To investigate this effect, increasing amounts of lactic acid were added to milk and to urease-treated milk, as described in Materials and Methods (Figure 1A). The difference of $\mathrm{pH}$ between the 2 samples reflects the effect of urea hydrolysis at different concentrations of lactic acid (Figure 1B). This difference decreased dramatically when the concentration of lactic acid increased, and at a concentration of $10 \mathrm{~g} / \mathrm{L}$, it was only of about $0.06 \mathrm{U}$. This is the consequence of an increase of the buffering capacity of milk in the presence of lactic acid. It is possible that the buffering properties of milk in titration experiments are not strictly equivalent to those of milk fermented by $S$. thermophilus. Indeed, increase of the buffering capacity at low $\mathrm{pH}$ may be due to solubilization of colloidal calcium phosphate (Lucey et al., 1993), which may differ according to the acidification rate (acidification is faster in titration experiments than in growth experiments). However, the difference of $\mathrm{pH}$ between milk and urease-treated milk in titration experiments is probably a good indication of the impact of urea hydrolysis by $S$. thermophilus. Indeed, if there is a slight difference between the buffering properties of milk in titration experiments and those in $S$. thermophilus cultures, this difference should be the same when milk is treated or not with urease. 

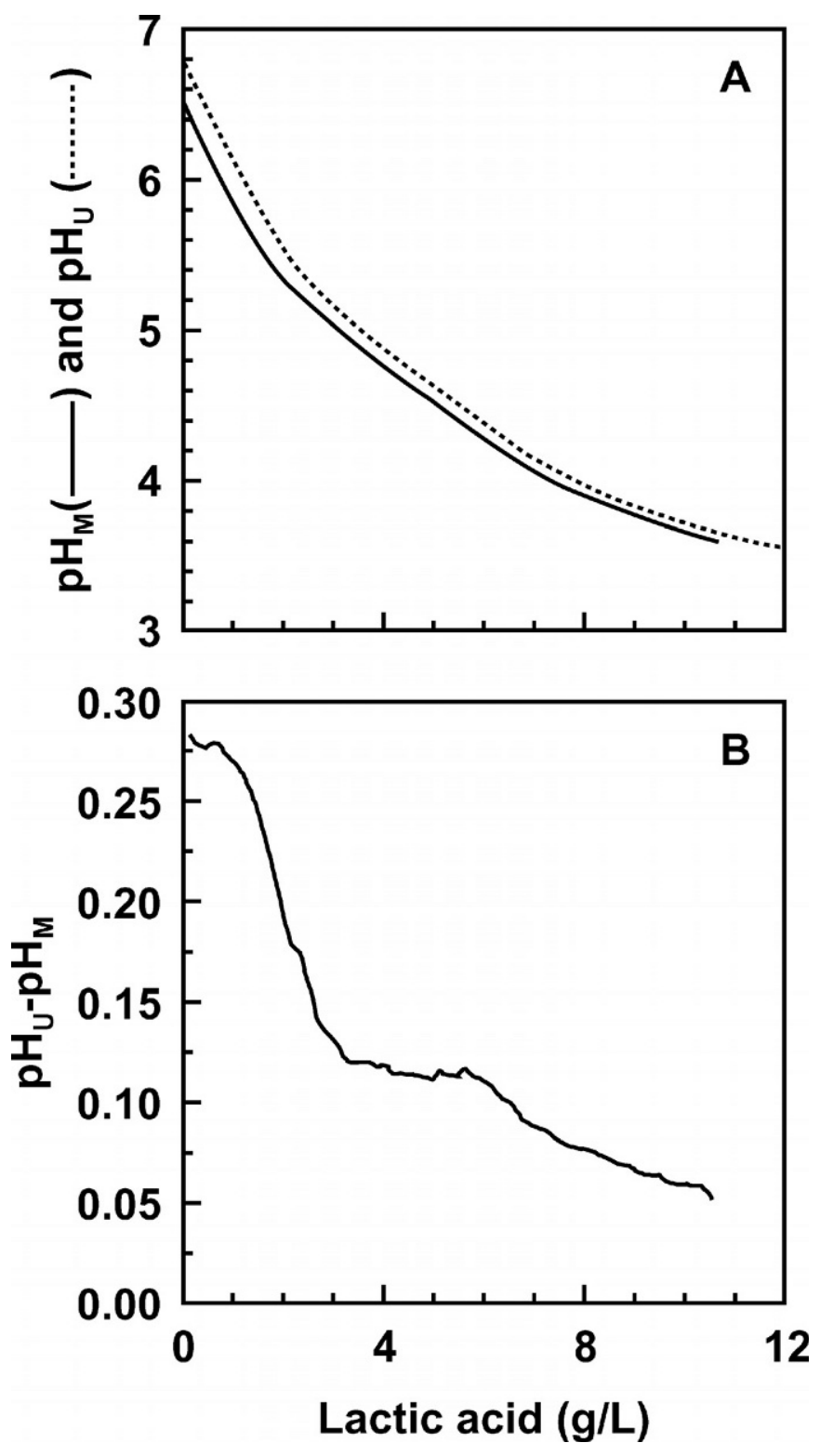

Figure 1. Effect of lactic acid addition on the $\mathrm{pH}$ of milk $\left(\mathrm{pH}_{\mathrm{M}}\right)$ and of urease-treated milk $\left(\mathrm{pH}_{\mathrm{U}}\right)(\mathrm{A})$, and evolution of the value of $\mathrm{pH}_{\mathrm{U}}-\mathrm{pH}_{\mathrm{M}}$ (B).

\section{Effect of the Metabolism of Urea on the Acidifying Activity of S. thermophilus}

The milk titration experiments with lactic acid described previously suggest that, when urea is consumed late during the growth of $S$. thermophilus (high lactic acid concentration), the decrease in the acidification rate due to the production of ammonia will be lower than when it is consumed early (low lactic acid concentration). However, the effect of the metabolism of urea on milk acidification may not be limited to the effect of ammonia on the $\mathrm{pH}$. Indeed, consumption of urea by
S. thermophilus may also modify the rate of lactic acid production. This might occur, for example, if the metabolism of urea significantly affects the growth of $S$. thermophilus. One way to evaluate this effect would be to compare milk cultures in the presence and in the absence of an urease inhibitor. Acetohydroxamate is a widely used urease inhibitor (Andrews et al., 1984), but it was unsatisfactory for the present investigation, as it did not completely inhibit the consumption of urea by growing $S$. thermophilus cells, even at a concentration of $5 \mathrm{~m} M$. This was not the case for the substrate analog flurofamide, which was used at a final concentration of $10 \mu M$. In order to establish that flurofamide acts only on urea hydrolysis, it was necessary to check that addition of this compound had no effect during cultivation of $S$. thermophilus in a medium devoid of urea. For this purpose, strains RD672, RD674, RD677, and RD678 were grown in urease-treated milk. In these experiments, addition of flurofamide did not change growth and acidification (data not shown). Furthermore, in milk that was not treated with urease, flurofamide had no effect on the growth and acidifying activity of the urease-deficient strain CNRZ407 described by Juillard and coworkers (1988). It can thus be concluded that in milk, flurofamide has no effect on growth and acidification of $S$. thermophilus, except the effect resulting from the inhibition of urease.

In the absence of flurofamide (i.e., when the strains are able to use urea), $S$. thermophilus RD674 and RD677 were more acidifying than strains RD672 and RD678 (Figure 2). Indeed, after $15 \mathrm{~h}$ of growth, their $\mathrm{pH}$ was lower than 4.5 , whereas it was higher than 5.0 for the other strains. Furthermore, growth of these strains was higher (Table 1). In the absence of flurofamide, there was a temporary decrease of the acidification rate between 160 and 250 min during the growth of strain $\mathrm{RD} 672$, as the $\mathrm{dpH} / \mathrm{dt}$ value increased (Figure $2)$. For strain RD678, there was even a temporary increase of $\mathrm{pH}$ between 150 and $230 \mathrm{~min}$. For the 2 other strains, no temporary increase of $\mathrm{pH}$ or of $\mathrm{dpH} / \mathrm{dt}$ could be observed at the beginning of the growth of the cultures, but there was a quasi-stagnation of $\mathrm{dpH} / \mathrm{dt}$ between 100 and 150 min. For the 4 strains, milk urea $(3.1 \mathrm{mM})$ was completely consumed during the growth of the cultures.

Depending on the strains, addition of flurofamide (urea consumption by the strains is then inhibited) had varying effects on the $\mathrm{pH}$ evolution kinetics. For strain $\mathrm{RD} 672$, a stimulation of the $\mathrm{pH}$ decrease was observed, especially between 200 and $600 \mathrm{~min}$ (Figure 2). This stimulating effect was higher for strain RD678, whereas it was lower for strain RD674. In the case of strain RD677, addition of flurofamide stimulated the $\mathrm{pH}$ decrease until $200 \mathrm{~min}$, and the opposite was subse- 

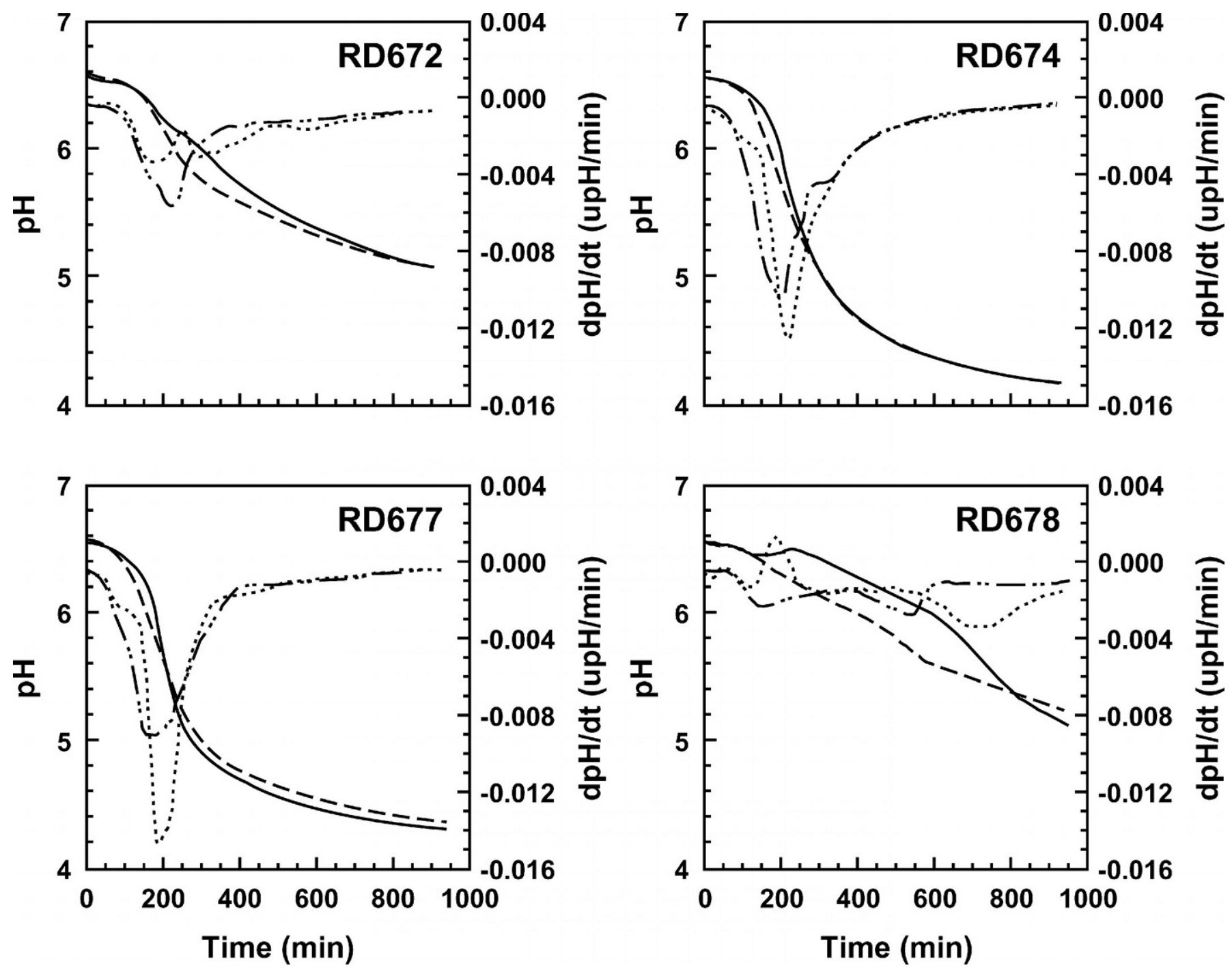

Figure 2. Evolution of the $\mathrm{pH}$ and its first time derivative (dpH/dt) during the growth of $S$. thermophilus RD672, RD674, RD677 and RD678 in milk. $\mathrm{pH}$ in the presence (- - - ) and in the absence (-) of flurofamide, and dpH/dt in the presence (- $-\longrightarrow$ ) and in the absence $(\cdots)$ of flurofamide.

Table 1. Effect of the urease inhibitor flurofamide on growth and lactic acid production by S. thermophilus. Strains were grown for $15 \mathrm{~h}$ in reconstituted skim milk. ${ }^{1,2}$

\begin{tabular}{llll}
\hline Strain & Flurofamide & $\begin{array}{l}\text { Growth } \\
\text { (absorbance at } 405 \mathrm{~nm})\end{array}$ & Lactic acid $(\mathrm{g} / \mathrm{L})$ \\
\hline RD672 & - & 1.72 & 3.22 \\
& + & $2.32^{3}$ & $2.92^{3}$ \\
RD674 & - & 6.37 & 6.88 \\
& + & $5.78^{3}$ & $6.17^{3}$ \\
RD677 & - & 6.90 & 6.20 \\
& + & $6.60^{3}$ & $5.69^{3}$ \\
RD678 & - & 1.66 & 2.85 \\
& + & $1.42^{3}$ & $2.04^{3}$ \\
\hline
\end{tabular}

${ }^{1}$ The values are means of three repetitions. Standard errors were always lower than $5 \%$.

${ }^{2}$ Urea concentration in reconstituted skim milk was $3.1 \mathrm{mM}$.

${ }^{3}$ Values were different from those in absence of flurofamide $(P<0.05)$. 


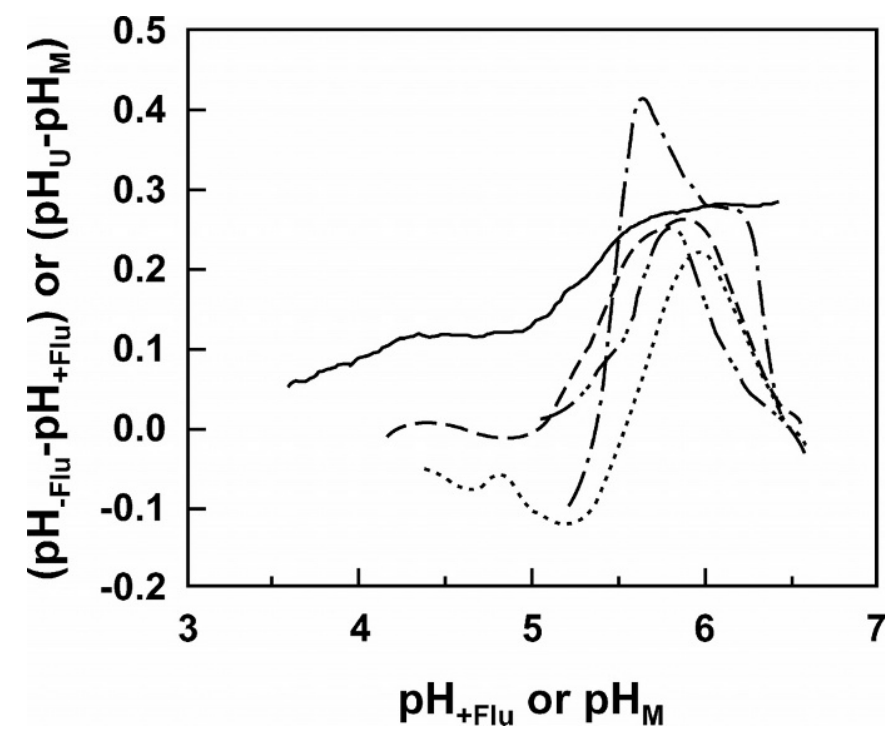

Figure 3. Evolution of the difference of $\mathrm{pH}$ between culture experiments of Streptococcus thermophilus RD672 (— - — — ), RD674 $(----), \operatorname{RD} 677(\cdots)$ and $\operatorname{RD} 678(-\cdot-)$ in the presence $\left(\mathrm{pH}_{+\mathrm{Flu}}\right)$ and in the absence $\left(\mathrm{pH}_{-\mathrm{Flu}}\right)$ of flurofamide, as a function of $\mathrm{pH}_{+\mathrm{Flu}}$. The difference of $\mathrm{pH}$ between milk $\left(\mathrm{pH}_{\mathrm{M}}\right)$ and urease-treated milk $\left(\mathrm{pH}_{\mathrm{U}}\right)$ as a function of $\mathrm{pH}_{\mathrm{M}}$ (data from milk titration experiments with lactic acid presented in Figure 1) is also shown (-).

quently observed. The temporary increase (strains RD672 and RD678) or stagnation (strains RD674 and $\mathrm{RD} 677$ ) of $\mathrm{dpH} / \mathrm{dt}$ that was observed at the beginning of the culturing time in the absence of flurofamide (when strains are able to use urea), did not occur when urea consumption was inhibited. Similar $\mathrm{pH}$ curves were obtained when culture experiments (in the presence or in the absence of flurofamide) were repeated (at all cultivation times, difference of $\mathrm{pH}$ between repeated cultures was always lower than $0.04 \mathrm{U}$ for strains RD672, RD674, and RD677, and $0.09 \mathrm{U}$ for RD678).

Figure 3 shows the curves relating the difference of $\mathrm{pH}$ between the culture experiments carried out in the presence and in the absence of flurofamide, as a function of the $\mathrm{pH}$ of the culture experiments in the presence of flurofamide. These curves characterize the effect of the metabolism of urea on the acidifying activity of $S$. thermophilus. The curve representing the difference of $\mathrm{pH}$ between milk and urease-treated milk as a function of $\mathrm{pH}$ (data from milk titration experiments with lactic acid presented in Figure 1) is also shown. It represents the direct effect of urea hydrolysis on $\mathrm{pH}$ (i.e., via the effect of ammonia and carbon dioxide production on $\mathrm{pH})$ and will be named hereafter "titration curve." The curves obtained for strains RD672, RD674, and RD677 have a similar profile, showing three distinct phases. During the first phase, from $\mathrm{pH} 6.6$ to about 6.0 to 5.8, they tend to increase and to come close to the titration curve. This phase corresponds to the consumption of urea by $S$. thermophilus. At the end of this phase, nearly all urea $(>95 \%)$ had been consumed. During the second phase, the 3 curves are close to the titration curve, especially for strains RD672 and RD674. At this growth stage of the cultures, the impact of the metabolism of urea on the acidifying activity of $S$. thermophilus was thus equivalent to the direct effect of ammonia and carbon dioxide on the $\mathrm{pH}$. In the third phase, the 3 curves tend to decrease and to move away from the titration curve. This may be explained by a higher production of lactic acid by $S$. thermophilus in the absence of flurofamide (i.e., when strains are able to use urea). Indeed, if urea consumption by $S$. thermophilus also increases its production of lactic acid, the $\mathrm{pH}$-increasing effect of urea consumption (via production of ammonia) would thus be compensated for by the $\mathrm{pH}$-decreasing effect due to increased lactic acid production. Measurements of lactic acid concentration at the end of growth of the cultures confirmed that urea consumption (cultivation in the absence of flurofamide) increases lactic acid production (Table 1). The curve corresponding to strain RD678 (Figure 3) was similar to those of the three other strains, except that it was higher than the titration curve from $\mathrm{pH} 6.0$ to 5.5. This may be explained by a temporary inhibition of lactic acid production by this strain in the absence of flurofamide (i.e., when the strain is able to use urea). For strains RD674, RD677, and RD678, addition of flurofamide decreased growth after $15 \mathrm{~h}$, whereas the reverse was observed for strain RD672 (Table 1).

\section{DISCUSSION}

The objective of the present study was to investigate the effect of the metabolism of urea on the acidifying activity of $S$. thermophilus. The urease present in this bacterium converts urea into ammonia $(\mathrm{pK}=9.24)$ and carbon dioxide, which combines with water to form carbonic acid $(\mathrm{pK}=6.35)$. As the production of ammonia is twice that of carbonic acid and the $\mathrm{pH}$ of milk is much lower than the $\mathrm{pK}$ of ammonia, urea hydrolysis tends to increase the $\mathrm{pH}$. Our results show that this effect is much higher when it occurs at low lactic acid concentration (i.e., in conditions equivalent to the beginning of growth), than at high lactic acid concentration (i.e., in conditions equivalent to the end of growth). Consequently, it is expected that for fast-acidifying strains and for strains that consume urea late during growth of the culture, the effect of the metabolism of urea on the evolution of $\mathrm{pH}$ is limited. It is interesting to note that variations of acidifying activity due to urea consumption by $S$. thermophilus are known to occur especially in cheese-manufacturing processes in which acid- 
ification is slow. Furthermore, the effect of urea consumption on the evolution of $\mathrm{pH}$ (which was evaluated by comparing culture experiments in the presence and in the absence of flurofamide) during the growth of the 2 slow-acidifying strains used in the study, was greater than for the fast-acidifying strains.

However, the effect of the metabolism of urea on the acidifying activity of $S$. thermophilus cannot be attributed to the sole effect of ammonia and carbon dioxide on $\mathrm{pH}$. Indeed, experiments with the urease inhibitor flurofamide enabled us to show that urea consumption also affects lactic acid production by $S$. thermophilus. For 3 of the 4 strains investigated, urea consumption increased lactic acid production, which tends to counteract the $\mathrm{pH}$-increasing effect of urea hydrolysis. This may be linked to a stimulation of growth by urea, but not only, as no increased growth was observed for strain RD672. For the fourth strain (RD678), urea consumption considerably reduced the decrease in $\mathrm{pH}$ during part of growth of the culture. This effect is probably the result of a temporary decrease in lactic acid production. The present study also shows that the effect of urea metabolism on the acidifying activity of slow-acidifying $S$. thermophilus strains may be very different depending on the strain. For example, for S. thermophilus $\mathrm{RD} 678$, the metabolism of urea was responsible for an increase of $195 \mathrm{~min}$ of the time necessary to reach $\mathrm{pH}$ 6 (Figure 2), whereas this increase was $65 \mathrm{~min}$ for strain RD672.

In order to better understand the effect of urea on the growth and acidifying activity of $S$. thermophilus, it would be interesting to investigate all the physiological consequences of the metabolism of urea. For example, it is possible that some ammonia and carbon dioxide produced from urea may be used for the synthesis of cellular components during the growth of $S$. thermophilus in milk. Urea consumption may also have an effect on the intracellular $\mathrm{pH}$ of $S$. thermophilus.

\section{CONCLUSIONS}

Utilization of the urease inhibitor flurofamide makes it easy to characterize the effect of urea on $\mathrm{pH}$ evolution kinetics during the growth of $S$. thermophilus in milk. Depending on the strains and the growth stages of the cultures, consumption of urea induces, either a faster or a slower $\mathrm{pH}$ decrease. We suggest that selection of strains used in cheese-manufacturing processes should include characterization of the effect of urea. This will be useful for limiting the variations of $\mathrm{pH}$ evolution kinetics due to the consumption of urea by $S$. thermophilus.

\section{ACKNOWLEDGMENTS}

We are grateful to Christine Young for critically reading the manuscript.

\section{REFERENCES}

Andrews, R. K., R. L. Blakeley, and B. Zerner. 1984. Urea and urease. Adv. Inorg. Biochem. 6:245-283.

de Peters, E. J., and J. D. Ferguson. 1992. Nonprotein nitrogen and protein distribution in the milk of cows. J. Dairy Sci. 75:31923209.

Juillard, V., M. J. Desmazeaud, and H. E. Spinnler. 1988. Mise en évidence d'une activité uréasique chez Streptococcus thermophilus. Can. J. Microbiol. 34:818-822.

Kenny, G. E. 1983. Inhibition of the growth of Ureaplasma urealyticum by a new urease inhibitor, flurofamide. Yale J. Biol. Med. 56:717-722.

Kohn, R. A., K. F. Kalscheur, and E. Russek-Cohen. 2002. Evaluation of models to estimate urinary nitrogen and expected milk urea nitrogen. J. Dairy Sci. 85:227-233.

Latrille, E., D. Picque, B. Perret, and G. Corrieu. 1992. Characterizing acidification kinetics by measuring $\mathrm{pH}$ and electrical conductivity in batch thermophilic lactic fermentations. J. Ferment. Bioeng. 74:32-38.

Levata-Jovanovic, M., and W. E. Sandine. 1996. Citrate utilization and diacetyl production by various strains of Leuconostoc mesenteroides ssp. cremoris. J. Dairy Sci. 79:1928-1935.

Lucey, J. A., B. Hauth, C. Gorry, and P. F. Fox. 1993. The acid-base buffering properties of milk. Milchwissenschaft. 48:268-272.

Martin, B., J. B. Coulon, J. F. Chamba, and C. Bugaud. 1997. Effect of milk urea content on characteristics of matured Reblochon cheeses. Lait 77:505-514.

Monnet, C., A. El Attar, and G. Corrieu. 2002. Production of carbon dioxide by Lactococcus lactis strains with attenuated lactate dehydrogenase activity, in pure cultures and in mixed cultures with an acidifying strain. Lait 82:267-279.

Spinnler, H. E., and G. Corrieu. 1989. Automatic method to quantify starter activity based on $\mathrm{pH}$ measurement. J. Dairy Res. $56: 755-764$.

Terzaghi, B. E., and W. E. Sandine. 1975. Improved medium for lactic streptococci and their bacteriophages. Appl. Microbiol. 29:807813.

Tinson, W., M. C. Broome, A. J. Hillier, and G. R. Jago. 1982. Metabolism of Streptococcus thermophilus. 2. Production of $\mathrm{CO}_{2}$ and $\mathrm{NH}_{3}$ from urea. Aust. J. Dairy Technol. 37:14-16. 